CLINICAL STUDY

\title{
Higher free thyroxine levels are associated with all-cause mortality in euthyroid older men: the Health In Men Study
}

\author{
Bu B Yeap ${ }^{1,2}$, Helman Alfonso ${ }^{3}$, Graeme $\mathrm{J} \mathrm{Hankey}^{1}$, Leon Flicker ${ }^{1,3}$, Jonathan Golledge ${ }^{4}$, \\ Paul E Norman ${ }^{5}$ and S A Paul Chubb ${ }^{1,6}$ \\ ${ }^{1}$ School of Medicine and Pharmacology, University of Western Australia, Perth, Western Australia, Australia, ${ }^{2}$ Department of Endocrinology and Diabetes, \\ Fremantle Hospital, Fremantle, Western Australia, Australia, ${ }^{3}$ Western Australian Centre for Health and Ageing, Centre for Medical Research, University of \\ Western Australia, Perth, Western Australia, Australia, ${ }^{4}$ Vascular Biology Unit, School of Medicine and Dentistry, James Cook University, Townsville, \\ Queensland, Australia, ${ }^{5}$ School of Surgery, University of Western Australia, Perth, Western Australia, Australia and ${ }^{6}$ PathWest Laboratory Medicine, \\ Fremantle and Royal Perth Hospitals, Perth, Western Australia, Australia
}

(Correspondence should be addressed to B B Yeap at School of Medicine and Pharmacology, University of Western Australia; Email: byeap@cyllene.uwa.edu.au)

\begin{abstract}
Objective: Thyroid dysfunction predicts poorer health outcomes, but the relationship between thyroid hormone levels within the reference range and mortality in older adults remains unclear. In this study, we examined the associations between the concentrations of free thyroxine $\left(\mathrm{FT}_{4}\right)$ and TSH and allcause mortality in older men without thyroid disease.

Subjects and methods: We performed a longitudinal study in community-dwelling men aged 70-89 years. Men with thyroid disease or taking thyroid-related medications were excluded. Baseline $\mathrm{FT}_{4}$ and TSH levels were assayed. Incident deaths were ascertained using data linkage.

Results: There were 3885 men without thyroid disease followed for (mean \pm s.D.) $6.4 \pm 1.5$ years, during which time 837 had died $(21.5 \%)$. Men who had died had higher baseline $\mathrm{FT}_{4}$ levels $(16.2 \pm 2.3$ vs $15.8 \pm 2.1 \mathrm{pmol} / \mathrm{l}, P<0.001)$, but comparable TSH levels $(2.4 \pm 1.5 \mathrm{vs} 2.3 \pm 1.5 \mathrm{mIU} / \mathrm{l}$, $P=0.250$ ). After accounting for age, smoking, physical factors and medical comorbidities, higher circulating $\mathrm{FT}_{4}$ levels predicted all-cause mortality (quartile Q4 vs quartiles Q1-Q3: $\mathrm{FT}_{4}$ levels $\geq 17.32$ vs $<17.32 \mathrm{pmol} / \mathrm{l}$ : adjusted hazard ratio $(\mathrm{HR})=1.19,95 \% \mathrm{CI}=1.02-1.39, P=0.025)$. TSH levels did not predict mortality. After excluding men with subclinical hyperthyroidism or hypothyroidism, there were 3442 men and 737 who had died (21.4\%). In these men, higher $\mathrm{FT}_{4}$ levels remained independently associated with all-cause mortality (quartile Q4 vs quartiles Q1-Q3: adjusted $\mathrm{HR}=1.19,95 \% \mathrm{CI}=1.02-1.41, \mathrm{P}=0.032$ ).

Conclusions: Higher $\mathrm{FT}_{4}$ levels are associated with all-cause mortality in euthyroid older men, independently of conventional risk factors and medical comorbidities. Additional research is needed to determine whether or not this relationship is causal and to clarify the utility of thyroid function testing to stratify mortality risk in ageing men.
\end{abstract}

European Journal of Endocrinology 169 401-408

\section{Introduction}

Clinically recognisable syndromes of hyperthyroidism or hypothyroidism are responsive to treatments that normalise thyroid hormone levels, leading to the relief of symptoms and improvement of clinical outcomes. Subclinical hyperthyroidism is defined as low or suppressed TSH concentrations and circulating thyroid hormone levels within the reference range (1). The associations of subclinical hyperthyroidism with an increased risk of atrial fibrillation and with all-cause and coronary heart disease mortality have been reported $(2,3)$. Subclinical hypothyroidism is defined as elevated TSH concentrations with circulating thyroid hormone levels within the reference range and is associated with an increased risk of coronary heart disease if TSH levels exceed $10 \mathrm{mIU} / \mathrm{l}(4,5)$. Both higher and lower TSH levels have been reported to be associated with heart failure events (6). Consensus clinical guidelines based largely on observational studies recommend consideration of intervention in people with TSH levels $<0.1 \mathrm{mIU} / \mathrm{l}$ in the case of subclinical hyperthyroidism or TSH levels $>10 \mathrm{mIU} / \mathrm{l}$ in the case of subclinical hypothyroidism $(1,7)$. However, reversion to euthyroid hormone levels can occur in the absence of intervention (8), and data from randomised clinical trials are lacking to clarify the optimal management of people found to have subclinical thyroid disease.

It has been reported that an increase in TSH levels occurs during ageing, while free thyroxine $\left(\mathrm{FT}_{4}\right)$ levels 
remain relatively stable $(9,10,11)$. This may reflect reduced sensitivity of the pituitary to $\mathrm{T}_{4}$ - or liothyronine $\left(\mathrm{T}_{3}\right)$-mediated suppression of TSH levels, altered TSH bioactivity or reduced thyroid sensitivity to TSH, requiring compensatory elevation of levels to maintain thyroid homeostasis (10). Small differences in thyroid function between euthyroid subjects have been reported to be associated with specific health-related outcomes including atrial fibrillation, reduced bone mineral density and incident dementia $(12,13,14)$. However, the effect of differences in thyroid function in euthyroid older people on the key outcome of mortality remains unclear, with limited available data and inconsistent findings reported $(11,15,16,17)$. In this study, we tested the hypothesis that thyroid hormone levels within the normal range are an independent predictor of mortality in a large cohort of community-dwelling older men.

\section{Subjects and methods}

\section{Study population}

The recruitment of participants has been described in depth previously (18). Briefly, between 1996 and 1999, 19352 men were randomly selected from the electoral roll (with enrolment to vote being compulsory for Australian citizens) and invited to join a screening trial of abdominal aortic aneurysm. Of these, 12203 men $(63.1 \%)$ visited a clinic and completed a questionnaire that assessed a range of demographic and clinical data (Wave 1). Men were almost entirely of Caucasian ethnic origin. Between 2001 and 2004, the surviving men $(n=10940)$ were encouraged to participate in a followup study: 4249 agreed to donate an early-morning blood sample (Wave 2) and represent our study cohort. The Human Research Ethics Committee of the University of Western Australia approved the study protocol, and all men provided written informed consent to participate in the study.

\section{Physical measurements and medical comorbidities}

Height $(\mathrm{cm})$, weight $(\mathrm{kg})$ and blood pressure were measured in clinic attendees during Waves 1 and 2 . Questionnaire and clinical data obtained during Waves 1 and 2 were used to identify men with existing illnesses. Men were considered to have hypertension if they reported being diagnosed to have the condition by a doctor or were using anti-hypertensive medications (ATC codes C02, C03, C07, C08 and C09). Dyslipidaemia was defined as having HDL levels $<0.9 \mathrm{mmol} / \mathrm{l}, \mathrm{LDL}$ levels $\geq 3.4 \mathrm{mmol} / \mathrm{l}$, triglyceride levels $\geq 1.8 \mathrm{mmol} / \mathrm{l}$ or total cholesterol levels $\geq 5.5 \mathrm{mmol} / \mathrm{l}$ or if they were undergoing lipid-lowering therapy (ATC code C10). Questionnaire data obtained during Waves 1 and 2 and biochemical assessment data obtained during Wave 2 were used to identify men with diabetes. Men who had been diagnosed with the condition reported the use of glucose-lowering medications (ATC code A10) or had fasting or non-fasting glucose levels $\geq 7$ or $\geq 11.1 \mathrm{mmol} / \mathrm{l}$ respectively were considered to have diabetes. The presence of medical comorbidities was assessed using the Charlson index, which takes into account 17 common medical conditions that predict 1-year mortality: myocardial infarction, congestive heart failure, peripheral arterial disease, cerebrovascular disease, dementia, chronic pulmonary disease, connective tissue disease, ulcer disease, liver disease, diabetes (including diabetes with end organ damage), hemiplegia, renal disease, leukaemia, lymphoma, other tumours, metastatic tumours and AIDS (19). Medical diagnoses were weighted for severity and summed to provide a weighted index of medical comorbidity.

\section{Identification of men with existing thyroid diseases}

Questionnaire data obtained during Waves 1 and 2 were evaluated to identify men with existing thyroid diseases at baseline including those with a history of thyroidectomy, treatment with radioactive iodine or use of thyroid-related medications. In addition, we used the Western Australian Data Linkage System (WADLS) (20) to ascertain the presence of thyroid disorders. Briefly, the WADLS links together records from the Mental Health Information System, cancer register, death register and hospital morbidity data (which includes codes for multiple medical diagnoses for all admissions to private and public hospitals). Data were collected from 1990 to the time of blood sampling. The following thyroid disorders (ICD-10 codes) were used to identify men with thyroid disorders: iodine deficiency (E00, E01 and E02), established hypothyroidism or hyperthyroidism (E03 and E05), thyroiditis (E06), non-toxic goitre (E04) and other specified disorders of the thyroid (E07.8). The ICD-9 codes 240.x-246.x were also used for this purpose.

\section{Ascertainment of incident deaths}

The occurrence of death was ascertained using the WADLS (20), which contains both the original death certificate and an ICD-10-coded record generated from these data and other sources by the Australian Bureau of Statistics. The primary outcome was the occurrence of death from any cause. At the time of linkage, all deaths occurring in Western Australia up to the end of December 2010 were considered to have been recorded in the WADLS. The surviving men were censored 7 years after the collection of blood samples or on 31 December 2010, whichever occurred earlier. 


\section{Biochemical assays}

Laboratory assays were performed on aliquots of serum and plasma prepared immediately after the collection of blood sampled during Wave 2 and stored at $-80{ }^{\circ} \mathrm{C}$ until the time of assay, as described previously (21). Briefly, serum TSH and plasma $\mathrm{FT}_{4}$ concentrations were measured using an Elecsys 2010 immunoanalyser (Roche Diagnostics Australia). Between-run imprecision values (coefficient of variation) were 4.5 and $4.2 \%$ at 0.4 and $5.0 \mathrm{mIU} / \mathrm{l} \mathrm{TSH}$ and 4.0 and $5.2 \%$ at $14 \mathrm{pmol} / \mathrm{l}$ and $37 \mathrm{pmol} / \mathrm{I} \mathrm{FT}_{4}$. Reference intervals for these assays were 0.4-4.0 mIU/l for TSH and 10-23 pmol/l for $\mathrm{FT}_{4}$.

\section{Statistical analyses}

The statistical package Stata version 12.1 (StataCorp, College Station, TX, USA) was used to analyse the data. Baseline descriptive data are reported as mean and S.D. or percentages (\%). Kaplan-Meier plots of cumulative mortality according to the quartiles of $\mathrm{FT}_{4}$ and $\mathrm{TSH}$ were constructed. For the primary longitudinal analysis, Cox proportional-hazards regression was performed to assess the associations of $\mathrm{FT}_{4}$ and $\mathrm{TSH}$ levels as continuous variables and also in quartiles with all-cause mortality. In regression analyses, adjustment was made for age and other factors that could plausibly affect an association with mortality. The models were age adjusted, with subsequent additional adjustment for smoking, BMI, waist:hip ratio; hypertension, dyslipidaemia and creatinine level; and then medical comorbidities using the Charlson index. Age, BMI, waist:hip ratio and creatinine level were modelled as continuous variables, while smoking, hypertension, dyslipidaemia and Charlson index scores were modelled as categorical variables. Schoenfeld residuals were examined to evaluate the proportional-hazards assumption. The analyses were repeated after exclusion of men with subclinical hyperthyroidism or hypothyroidism. A supplementary analysis was performed by stratifying men according to the quartiles of both $\mathrm{FT}_{4}$ and TSH. A sensitivity analysis was performed by excluding men who reported the use of frusemide. A $P$ value $<0.05$ was considered significant.

\section{Results}

\section{Study population}

The disposition of the study participants is shown in Fig. 1. Of 4249 community-dwelling men aged 70-89 years assessed during Wave 2, 139 men who had a history of thyroid disease, thyroid surgery or treatment with radioactive iodine were excluded, as were 119 men taking thyroid-related medications, glucocorticoids or amiodarone and 82 men with missing data. We excluded five men with previously undiagnosed hyperthyroidism (TSH levels $<0.4 \mathrm{mU} / \mathrm{l}$ and $\mathrm{FT}_{4}$ levels $>23 \mathrm{pmol} / \mathrm{l}$ ) and nine men with undiagnosed hypothyroidism (TSH levels

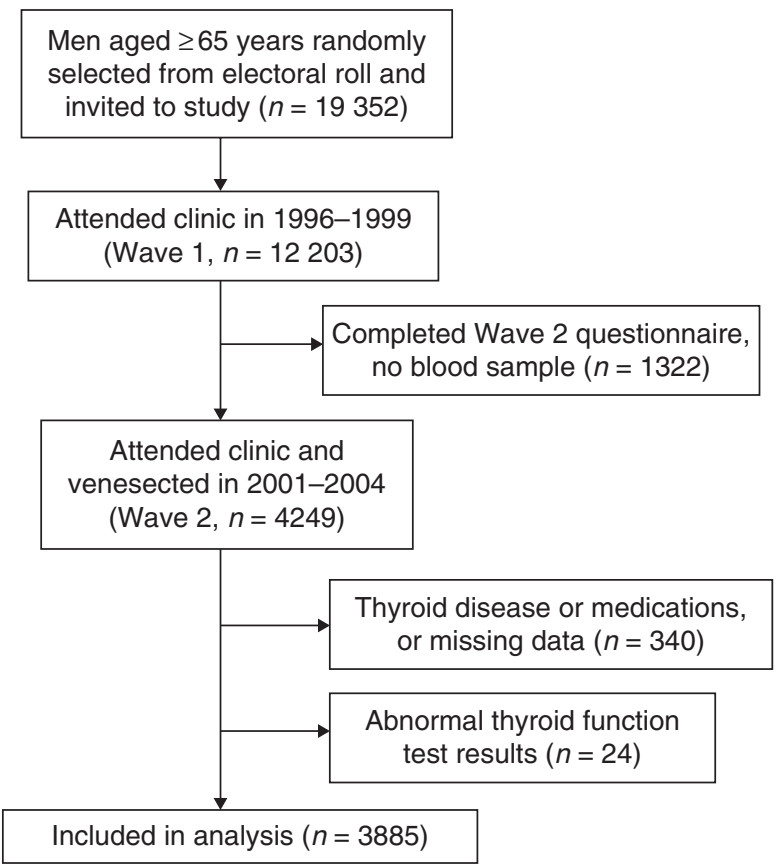

Figure 1 Study participant disposition scheme showing how the study cohort of 3885 men aged 70-89 years was derived.

$>4 \mathrm{mU} / \mathrm{l}$ and $\mathrm{FT}_{4}$ levels $\left.<10 \mathrm{pmol} / \mathrm{l}\right)$. We also excluded ten outliers who had very low or very high $\mathrm{FT}_{4}$ levels with normal TSH values. Following these exclusions, there were 3885 men for inclusion into the analysis (Fig. 1). In this cohort, the log-linear inverse association of TSH levels with $\mathrm{FT}_{4}$ levels was preserved (21). Western Australia is regarded as an iodine-sufficient region (22).

\section{Demographic, physical and medical characteristics}

The characteristics of the study population stratified according to survival status are presented in Table 1. Men were followed for a mean ( \pm s.D.) duration of $6.4 \pm$ 1.5 years, during which time 837 died (21.5\%). Men who had died were older and more likely to be past or current smokers and had a lower BMI but a higher waist:hip ratio at baseline than men who were still alive (Table 1). Men who had died were more likely to have hypertension, had more medical comorbidities as reflected in the higher Charlson index scores, and had higher baseline creatinine levels than the surviving men. Men who had died had higher baseline $\mathrm{FT}_{4}$ levels than men who did not die $(16.2 \pm 2.3$ vs $15.8 \pm$ $2.1 \mathrm{pmol} / \mathrm{l}, P<0.001)$. TSH levels were similar in both the groups $(2.4 \pm 1.5$ vs $2.3 \pm 1.5 \mathrm{mIU} / \mathrm{l}, P=0.250)$.

\section{Cumulative mortality in men according to $\mathrm{FT}_{4}$ and TSH levels}

Kaplan-Meier plots of cumulative mortality according to the quartiles of $\mathrm{FT}_{4}$ and TSH are shown in Fig. 2. Men 
Table 1 Demographic, physical and biochemical characteristics of the study population, stratified according to survival status. Data are means \pm s.D. or $n(\%)$.

\begin{tabular}{|c|c|c|c|}
\hline & $\begin{array}{c}\text { Alive } \\
(n=3048)\end{array}$ & $\begin{array}{c}\text { Died } \\
(n=837)\end{array}$ & $P$ value \\
\hline Age (years) & $76.6 \pm 3.4$ & $78.5 \pm 4.0$ & $<0.001$ \\
\hline Never smokers & 1093 (35.9) & $222(26.5)$ & $<0.001$ \\
\hline Past smokers & 1827 (59.9) & $542(64.8)$ & \\
\hline Current smokers & $127(4.2)$ & $71(8.5)$ & \\
\hline BMI $\left(\mathrm{kg} / \mathrm{m}^{2}\right)$ & $26.6 \pm 3.5$ & $26.2 \pm 3.9$ & 0.003 \\
\hline Waist:hip ratio & $0.97 \pm 0.07$ & $0.98 \pm 0.08$ & 0.005 \\
\hline Hypertension & 2518 (82.6) & $729(87.1)$ & 0.002 \\
\hline Dyslipidaemia & 1826 (59.9) & 488 (58.3) & 0.402 \\
\hline \multicolumn{4}{|l|}{ Charlson index } \\
\hline 0 & 1969 (64.6) & 384 (45.9) & $<0.001$ \\
\hline $1-2$ & $791(26.0)$ & $254(30.4)$ & \\
\hline $3-4$ & $213(7.0)$ & 125 (14.9) & \\
\hline$\geq 5$ & $74(2.4)$ & $74(8.8)$ & \\
\hline Creatinine $(\mu \mathrm{mol} / \mathrm{l})$ & $91.4 \pm 27.8$ & $99.1 \pm 39.3$ & $<0.001$ \\
\hline $\mathrm{FT}_{4}(\mathrm{pmol} / \mathrm{l})$ & $15.8 \pm 2.1$ & $16.2 \pm 2.3$ & $<0.001$ \\
\hline TSH (mIU/l) & $2.30 \pm 1.45$ & $2.35 \pm 1.51$ & 0.250 \\
\hline
\end{tabular}

OR, odds ratio.

with $\mathrm{FT}_{4}$ levels in the highest quartile of values exhibited increased cumulative mortality compared with men with $\mathrm{FT}_{4}$ levels in the other three quartiles (Fig. 2A). There was no apparent separation of curves for cumulative mortality according to the quartiles of TSH (Fig. 2B).

\section{No associations of subclinical thyroid disease with mortality}

There were 27 men $(0.7 \%)$ who were classified as having subclinical hyperthyroidism (TSH levels $<0.4 \mathrm{mU} / \mathrm{l}$ and $\mathrm{FT}_{4}$ levels $\left.10-23 \mathrm{pmol} / \mathrm{l}\right)$ and $416(10.7 \%)$ as having subclinical hypothyroidism (TSH levels $>4 \mathrm{mU} / \mathrm{l}$ and $\mathrm{FT}_{4}$ levels $\left.\geq 10 \mathrm{pmol} / \mathrm{l}\right)$. Four men with subclinical hyperthyroidism had died $(14.8 \%)$ and 95 with subclinical hypothyroidism (22.8\%). Compared with euthyroid men, there was no significant difference in all-cause mortality for men with subclinical hyperthyroidism (hazard ratio $(\mathrm{HR})=0.68,95 \% \mathrm{CI}=0.25-1.81$, $P=0.442)$ or subclinical hypothyroidism $(\mathrm{HR}=1.06$, 95\% CI $=0.86-1.32, P=0.573)$.

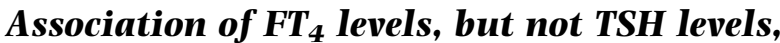 with mortality in older men}

The results of the Cox regression analyses of all-cause mortality according to $\mathrm{FT}_{4}$ and $\mathrm{TSH}$ levels in the whole cohort are given in Table 2 . In keeping with the results of the Kaplan-Meier analysis, men with $\mathrm{FT}_{4}$ levels in the highest quartile had an increased HR for all-cause mortality, which was reduced following adjustment for covariates (Table 2). In the fully adjusted model, there was a statistically significant difference in all-cause mortality for men with $\mathrm{FT}_{4}$ levels in the highest quartile and all other men (quartile Q4 vs quartiles Q1-Q3:
$\mathrm{HR}=1.19,95 \% \mathrm{CI}=1.02-1.39, P=0.025) . \mathrm{TSH}$ levels were not associated with all-cause mortality (Table 2).

\section{Association of $\mathrm{FT}_{4}$ levels with mortality in euthyroid older men}

After exclusion of all men with subclinical hyperthyroidism or hypothyroidism, there were 3442 euthyroid men and 737 men who had died $(21.4 \%)$. The results of the Cox regression analyses for these men are presented in Table 3. On comparing the men in the highest quartile of $\mathrm{FT}_{4}$ with other euthyroid men, a significantly increased risk for all-cause mortality was observed (quartile Q4 vs quartiles Q1-Q3: adjusted $\mathrm{HR}=1.19,95 \% \mathrm{CI}=1.02-1.41, P=0.032$ ). TSH levels were not associated with all-cause mortality in euthyroid men (Table 3).
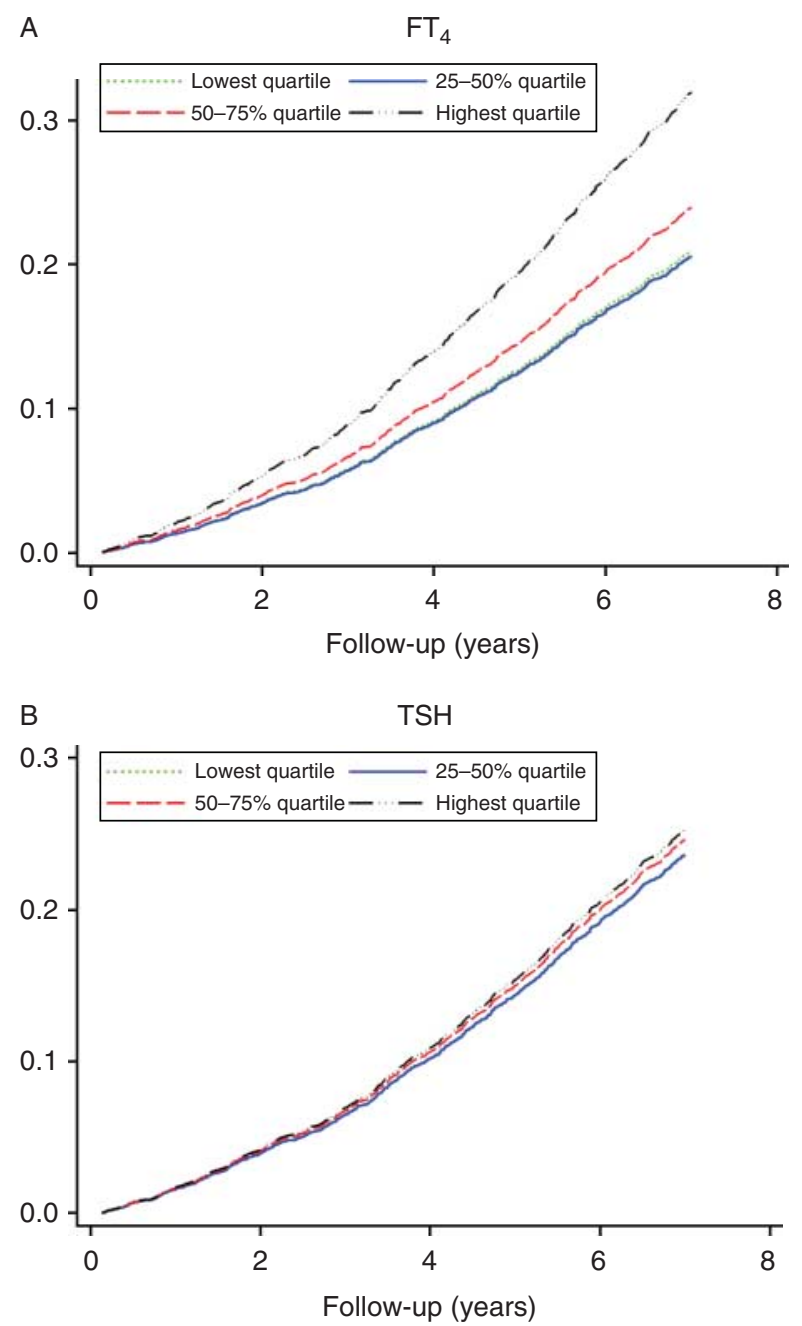

Figure 2 Cumulative hazard of all-cause mortality according to the quartiles of $\mathrm{FT}_{4}(\mathrm{~A})$ and TSH (B) in 3885 community-dwelling older men. $Y$-axis shows the cumulative risk of death from any cause and $\mathrm{X}$-axis shows the duration of follow-up in years. 
Table 2 Associations of free thyroxine $\left(\mathrm{FT}_{4}\right)$ and TSH levels in quartiles with all-cause mortality in 3885 community-dwelling men aged 7089 years.

\begin{tabular}{|c|c|c|c|c|c|c|c|}
\hline & Range & Died (\%) & $\begin{array}{c}\text { Univariate } \\
(\mathrm{HR}(95 \% \mathrm{Cl}))\end{array}$ & $\begin{array}{c}\text { Model } 1 \\
(\mathrm{HR}(95 \% \mathrm{Cl}))\end{array}$ & $\begin{array}{c}\text { Model } 2 \\
(\mathrm{HR}(95 \% \mathrm{Cl}))\end{array}$ & $\begin{array}{c}\text { Model 3 } \\
(\mathrm{HR}(95 \% \mathrm{Cl}))\end{array}$ & $\begin{array}{c}\text { Model } 4 \\
(\mathrm{HR}(95 \% \mathrm{Cl}))\end{array}$ \\
\hline \multicolumn{8}{|l|}{$\mathrm{FT}_{4}(\mathrm{pmol} / \mathrm{l})$} \\
\hline Q1 & $9.64-14.46$ & 19.1 & 1.00 (reference) & & & & \\
\hline Q2 & $14.47-15.78$ & 18.5 & $0.97(0.79-1.20)$ & $0.96(0.78-1.18)$ & $0.97(0.79-1.20)$ & $0.97(0.78-1.19)$ & $0.97(0.79-1.20)$ \\
\hline Q3 & $15.79-17.31$ & 21.3 & $1.13(0.93-1.39)$ & $1.05(0.86-1.29)$ & $0.99(0.81-1.22)$ & $0.96(0.79-1.18)$ & $0.94(0.77-1.16)$ \\
\hline Q4 & $17.32-24.05$ & 27.4 & $1.51(1.25-1.83)$ & $1.35(1.11-1.63)$ & $1.24(1.02-1.51)$ & $1.21(0.99-1.48)$ & $1.16(0.95-1.41)$ \\
\hline Q4 vs Q1-Q3 & $\geq 17.32$ & & $1.46(1.25-1.69)$ & $1.34(1.15-1.56)$ & $1.26(1.08-1.47)$ & $1.24(1.06-1.45)$ & $1.19(1.02-1.39)$ \\
\hline \multicolumn{8}{|c|}{ 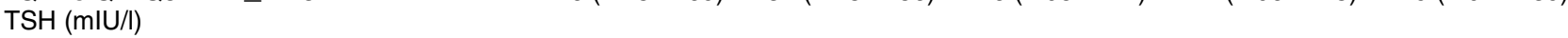 } \\
\hline Q1 & $0.01-1.40$ & 21.0 & 1.00 (reference) & & & & \\
\hline Q2 & $1.41-1.98$ & 21.0 & $1.00(0.82-1.21)$ & $1.00(0.82-1.21)$ & $0.99(0.81-1.20)$ & $0.99(0.81-1.20)$ & $0.97(0.80-1.18)$ \\
\hline Q3 & $1.99-2.80$ & 21.7 & $1.04(0.86-1.26)$ & $1.03(0.85-1.25)$ & $1.06(0.88-1.29)$ & $1.05(0.86-1.28)$ & $1.06(0.87-1.29)$ \\
\hline Q4 & $2.81-19.12$ & 22.4 & $1.07(0.88-1.30)$ & $1.00(0.83-1.22)$ & $1.02(0.84-1.24)$ & $1.00(0.82-1.21)$ & $0.98(0.81-1.20)$ \\
\hline Q1 vs Q2-Q4 & $\leq 1.40$ & & $0.96(0.82-1.13)$ & $0.99(0.84-1.16)$ & $0.97(0.83-1.14)$ & $0.99(0.84-1.16)$ & $1.00(0.85-1.17)$ \\
\hline
\end{tabular}

Q, quartile; HR, hazard ratio; Model 1, adjusted for age; Model 2, adjusted for age and for smoking, BMI and waist:hip ratio; Model 3, adjusted for variables in Model 2 and for hypertension, dyslipidaemia and creatinine level; Model 4, adjusted for variables in Model 3 and for medical comorbidity (Charlson index).

\section{Supplementary analysis: stratification by both $\mathrm{FT}_{4}$ and TSH levels}

Among the euthyroid men, there were 294 with $\mathrm{FT}_{4}$ levels in the highest quartile and TSH levels in the lowest quartile of values, of whom 79 had died $(26.9 \%)$. There were 177 men with $\mathrm{FT}_{4}$ levels in quartile $\mathrm{Q} 1$ and TSH levels in quartile Q4, of whom 37 (20.9\%) had died. In the multivariate regression analysis, there was no statistically significant difference in the risk of all-cause mortality for either group of men compared with the remaining men (adjusted $\mathrm{HR}=1.17,95 \%$ $\mathrm{CI}=0.92-1.48, \quad P=0.200$, and $1.05,0.75-1.47$, $P=0.775$ respectively).

\section{Sensitivity analysis}

Exclusion of men who were receiving frusemide reduced the statistical power available for the analysis, as there were 2942 men who were alive and 732 who had died. In 3674 men, the fully adjusted HR for all-cause mortality for men with $\mathrm{FT}_{4}$ levels in the highest quartile compared with other men was 1.14 (95\% CI $=0.96-1.34)$. In 3258 euthyroid men, the fully adjusted $\mathrm{HR}$ was $1.14(95 \% \mathrm{CI}=0.96-1.36)$.

\section{Discussion}

In community-dwelling men aged $\geq 70$ years free of overt thyroid disease at baseline, $\mathrm{FT}_{4}$ levels in the highest quartile of values predicted an increased allcause mortality risk, independently of covariates and medical comorbidities. After excluding men with either subclinical hyperthyroidism or subclinical hypothyroidism, $\mathrm{FT}_{4}$ levels remained an independent predictor of all-cause mortality in euthyroid men. Therefore, in older men, high-normal circulating $\mathrm{FT}_{4}$ levels may be a causal factor or a biomarker for mortality risk.

Previously, Gussekloo et al. (15) had reported that $\mathrm{FT}_{4}$ levels as a continuous variable were associated with an increased all-cause mortality risk in 588 adults aged $\geq 85$ years with normal TSH levels in their study cohort. In that study, low TSH levels predicted an

Table 3 Associations of free thyroxine $\left(\mathrm{FT}_{4}\right)$ and TSH levels in quartiles with all-cause mortality in 3442 euthyroid men aged $70-89$ years.

\begin{tabular}{|c|c|c|c|c|c|c|c|}
\hline & Range & Died (\%) & $\begin{array}{c}\text { Univariate } \\
(\mathrm{HR}(95 \% \mathrm{Cl}))\end{array}$ & $\begin{array}{c}\text { Model } 1 \\
(\mathrm{HR}(95 \% \mathrm{Cl}))\end{array}$ & $\begin{array}{c}\text { Model } 2 \\
(\mathrm{HR}(95 \% \mathrm{Cl}))\end{array}$ & $\begin{array}{c}\text { Model } 3 \\
(\mathrm{HR}(95 \% \mathrm{Cl}))\end{array}$ & $\begin{array}{c}\text { Model } 4 \\
(\mathrm{HR}(95 \% \mathrm{Cl}))\end{array}$ \\
\hline \multicolumn{8}{|l|}{$\mathrm{FT}_{4}(\mathrm{pmol} / \mathrm{l})$} \\
\hline Q1 & $9.64-14.46$ & 18.7 & 1.00 (reference) & & & & \\
\hline Q2 & $14.47-15.78$ & 17.8 & $0.96(0.76-1.20)$ & $0.94(0.75-1.18)$ & $0.96(0.76-1.21)$ & $0.96(0.76-1.20)$ & $0.98(0.78-1.23)$ \\
\hline Q3 & $15.79-17.31$ & 21.1 & $1.14(0.92-1.42)$ & $1.03(0.83-1.28)$ & $0.98(0.79-1.23)$ & $0.96(0.77-1.20)$ & $0.96(0.77-1.20)$ \\
\hline Q4 & $17.32-24.05$ & 27.7 & $1.56(1.27-1.92)$ & $1.35(1.09-1.66)$ & $1.25(1.01-1.54)$ & $1.22(0.98-1.51)$ & $1.17(0.94-1.44)$ \\
\hline Q4 vs Q1-Q3 & $\geq 17.32$ & & $1.51(1.29-1.77)$ & $1.36(1.16-1.59)$ & 1.27 (1.08-1.50) & $1.25(1.06-1.47)$ & $1.19(1.02-1.41)$ \\
\hline \multicolumn{8}{|l|}{ TSH (mIU/l) } \\
\hline Q1 & $0.42-1.40$ & 21.2 & 1.00 (reference) & & & & \\
\hline Q2 & $1.41-1.98$ & 21.0 & $0.99(0.81-1.20)$ & $0.98(0.81-1.19)$ & $0.98(0.80-1.19)$ & $0.98(0.80-1.19)$ & $0.96(0.79-1.17)$ \\
\hline Q3 & $1.99-2.80$ & 21.7 & $1.03(0.85-1.25)$ & $1.01(0.83-1.23)$ & $1.05(0.87-1.28)$ & $1.04(0.86-1.27)$ & $1.05(0.86-1.28)$ \\
\hline Q4 & $2.81-4.00$ & 21.9 & $1.04(0.83-1.30)$ & $1.02(0.82-1.28)$ & $1.02(0.82-1.28)$ & $1.00(0.80-1.26)$ & $0.99(0.79-1.25)$ \\
\hline Q1 vs Q2-Q4 & $\leq 1.40$ & & $0.98(0.84-1.16)$ & $1.00(0.85-1.17)$ & $0.98(0.83-1.16)$ & $0.99(0.84-1.17)$ & $1.00(0.85-1.18)$ \\
\hline
\end{tabular}

Q, quartile; HR, hazard ratio; Model 1, adjusted for age; Model 2, adjusted for age and for smoking, BMI and waist:hip ratio; Model 3, adjusted for variables in Model 2 and for hypertension, dyslipidaemia and creatinine level; Model 4, adjusted for variables in Model 3 and for medical comorbidity (Charlson index). 
increased mortality risk and the lowest mortality risk was observed in adults with high TSH levels and low $\mathrm{FT}_{4}$ levels. Waring et al. (11) reported an analysis of 843 long-term survivors from the Cardiovascular Health Study ('All-Stars') aged a mean of 85.3 years in whom higher $\mathrm{FT}_{4}$ levels, but not TSH levels, predicted mortality after adjustment for age, sex and race. However, it remained unclear whether a similar association was present in the more general population of older men rather than in the selected groups of the 'oldest old'. Furthermore, the possibility that medical comorbidity might have modulated or confounded these apparent relationships needed to be explored. In a study of 403 men aged 73-94 years, van den Beld et al. (16) reported $\mathrm{FT}_{4}$ levels, but not TSH levels, to be associated with 4-year mortality risk after adjustment for age. By contrast, in 1587 men aged $\geq 65$ years from the Osteoporotic Fractures in Men (MrOS) Study, Waring et al. (17) found that neither $\mathrm{FT}_{4}$ levels nor TSH levels predicted mortality in multivariate analyses. However, that study may have lacked the power to detect a moderate association as reflected in the wide CI observed. Our findings in a larger cohort of community-dwelling men aged $\geq 70$ years differ, as after adjustment for age, smoking, BMI, waist:hip ratio and medical comorbidities, $\mathrm{FT}_{4}$ levels in the highest quartile of values ( $\geq 17.3 \mathrm{pmol} / \mathrm{l})$ remained an independent and significant predictor of death from any cause. These associations were present in the cohort as a whole and in euthyroid men after exclusion of men with subclinical hyperthyroidism and hypothyroidism.

Collet et al. (3) pooled individual participant data from ten cohorts comprising 52674 participants for a meta-analysis and found that adults with subclinical hyperthyroidism had an increased risk of all-cause mortality after adjustment for age and sex $(\mathrm{HR}=1.29)$. Individual studies within this meta-analysis have examined middle-aged and older men and women and either measured TSH levels only (23) or measured $\mathrm{FT}_{4}$ levels selectively in the setting of abnormal TSH levels $(24,25)$ or did not report $\mathrm{FT}_{4}$ levels as an independent variable in relation to the outcome of mortality $(26,27$, $28,29,30,31)$. A recent study not included in that meta-analysis did not find associations of subclinical thyroid disease with mortality (32). We did not detect any significant association of subclinical hyperthyroidism with mortality. However, the number of men in that category was small $(n=27)$.

We did not find any association of TSH levels alone with all-cause mortality and nor did we find any significant excess of deaths in men with subclinical hypothyroidism. Several previous reports had not documented an association of subclinical hypothyroidism or higher TSH levels with mortality in men $(23,24$, 25, 26, 29, 30, 33). By contrast, in other studies, subclinical hypothyroidism has been reported to be associated with an increased risk of coronary events and mortality $(27,28,31)$. Explanations for these differences may be related to excess coronary events being more apparent in the relatively small number of men with TSH levels $\geq 10 \mathrm{mIU} / \mathrm{l}(4,5,6)$ or the possibility that the association between subclinical hypothyroidism and mortality risk may be more apparent in younger men than in older men (34).

The strengths of our study include the large sample size, the detailed characterisation of the men, the measurement of $\mathrm{TSH}$ and $\mathrm{FT}_{4}$ levels in the participants, the longitudinal nature of the study and the adjustment for multiple covariates. The focus on older men aged $\geq 70$ years is timely, as demographic change is expanding the population of older men and these men have higher mortality rates. The large number of outcome events provides the power to determine associations with precision. The data linkage is robust with hospital morbidity data comparable to adjudication of medical records (35), and follow-up is complete as deaths across all of Western Australia are captured and few men of this age migrate outside the state (20). We included medical comorbidities as assessed by the Charlson index as a covariate in the analysis.

We acknowledge several limitations of this study. The cohort comprised 4249 men derived from the original sample of 12203 men screened in 1996-1999 (18). Therefore, a 'healthy survivor' effect is possible. Consequently, our study cohort could be regarded as being more representative of healthier communitydwelling older men. Our study sample is almost entirely Caucasian; thus, the findings may not apply to younger men or men of other ethnic origins and we cannot comment on associations in women. Although finding an association of high $\mathrm{FT}_{4}$ levels with the risk of death from cardiovascular diseases could strengthen the argument for a causal association, data for specific causes of death are still being collated and verified, thus we could not analyse cause-specific mortality. While the longitudinal nature of the study is an advantage, these are observational data and causality cannot be confirmed. It is possible that $\mathrm{FT}_{4}$ levels are a biomarker rather than a causal factor for ill-health in ageing or that the higher $\mathrm{FT}_{4}$ levels resulted from an underlying predisposing cause. As frusemide has been reported to affect the assays of $\mathrm{FT}_{4}$ (36), we performed a sensitivity analysis excluding men taking frusemide. This reduced the HR from 1.19 to 1.14 , although not to 1.0 , suggesting that frusemide usage would not account entirely for the findings. Nevertheless, the magnitude of the association is moderate, and caution in extrapolating these findings to other groups is needed.

We measured $\mathrm{FT}_{4}$ and $\mathrm{TSH}$ levels in early-morning samples obtained at a single venesection and did not have the opportunity to collect serial specimens. However, intra-individual variability not captured by single sampling would be expected to attenuate rather than enhance any underlying associations. There is also the possibility that our results could have been confounded by the presence of non-thyroidal illness or 
'sick euthyroid' syndrome. In this scenario, men with non-thyroidal illness might exhibit abnormal thyroid hormone levels, although $\mathrm{FT}_{4}$ levels are typically low (7). However, our men were community dwelling rather than institutionalised and all voluntarily visited a study clinic for venesection, suggesting that they were not acutely unwell. Another limitation of the study is that we did not assay triiodothyronine levels.

Our results illuminate the association of $\mathrm{FT}_{4}$ levels with mortality in a large cohort of men aged $\geq 70$ years. The consideration of age may be relevant. It is possible that the effect of high-normal $\mathrm{FT}_{4}$ levels on mortality is subtle and cumulative, thus manifesting in older men and not in middle-aged men. Alternatively, ageassociated exposures to environmental, lifestyle or health-related factors may result in increased vulnerability to putative deleterious effects of high-normal $\mathrm{FT}_{4}$ levels in older men. Higher $\mathrm{FT}_{4}$ levels are associated with metabolically more favourable indices of lower total cholesterol and LDL levels and reduced insulin resistance $(37,38)$, but there are plausible biological mechanisms that may account for the association of high-normal $\mathrm{FT}_{4}$ levels with mortality. Excessive exposure to thyroid hormones exerts deleterious effects on cardiac rate, rhythm and function (39). In a study of 5860 adults aged $\geq 65$ years, Gammage et al. (12) reported that $\mathrm{FT}_{4}$ levels were independently associated with the presence of atrial fibrillation even in euthyroid subjects with normal TSH levels. Therefore, atrial fibrillation reflects one adverse cardiac consequence of excess thyroid hormone exposure on the cardiovascular system, which may be shared between people with subclinical hyperthyroidism and those with highnormal $\mathrm{FT}_{4}$ levels. Frailty is a syndrome characterised by the deterioration of multiple organ systems, leading to the loss of physiological reserve, diminished capacity to cope with stressors, and increased risk of disability and death (40). We have reported previously an association between higher $\mathrm{FT}_{4}$ levels and frailty in older men (21). Although we cannot discount the possibility that lower $\mathrm{FT}_{4}$ levels may be protective, the excess mortality risk was present for men with $\mathrm{FT}_{4}$ levels in the highest quartile of values. We postulate that exposure to $\mathrm{FT}_{4}$ levels in the higher end of the normal range may predispose to or be a biomarker for poorer health outcomes in ageing men.

In conclusion, higher $\mathrm{FT}_{4}$ levels are associated with all-cause mortality in older men, independently of conventional risk factors and medical comorbidities. Additional research is needed to determine whether or not this relationship is causal and to clarify the utility of thyroid function testing to stratify mortality risk in ageing men.

\section{Declaration of interest}

The authors declare that there is no conflict of interest that could be perceived as prejudicing the impartiality of the research reported.

\section{Funding}

B B Yeap is the recipient of a Clinical Investigator Award from the Sylvia and Charles Viertel Charitable Foundation, New South Wales, Australia. Hormone assays were funded by research grants from the Fremantle Hospital Medical Research Foundation, Fremantle Hospital, Western Australia, and the Ada Bartholomew Medical Research Trust, University of Western Australia. The Health In Men Study was funded by project grants $279408,379600,403963,513823$ and 634492 from the National Health and Medical Research Council of Australia. The funding sources had no involvement in the planning, analysis and writing of the manuscript.

\section{Acknowledgements}

The authors thank Roche Diagnostics Australia for the supply of assay reagents, the staff of PathWest Laboratory Medicine, Fremantle and Royal Perth Hospitals for their excellent technical assistance, and the staff and management of Shenton Park Hospital for their support. They especially thank all the men and staff who participated in the Western Australian Abdominal Aortic Aneurysm Program and the Health In Men Study.

\section{References}

1 Franklyn JA. The thyroid - too much and too little across the ages. The consequences of subclinical thyroid dysfunction. Clinical Endocrinology 201378 1-8. (doi:10.1111/cen.12011)

2 Biondi B \& Cooper DS. The clinical significance of subclinical thyroid dysfunction. Endocrine Reviews $2008 \quad 29$ 76-131. (doi:10.1210/er.2006-0043)

3 Collet T-H, Gussekloo J, Bauer DC, den Elzen WPJ, Cappola AR, Balmer P, Iervasi G, Asvold BO, Sgarbi JA, Volzke H et al. Subclinical hyperthyroidism and the risk of coronary heart disease and mortality. Archives of Internal Medicine 2012172 799-809. (doi:10.1001/archinternmed.2012.402)

4 Ochs N, Auer R, Bauer DC, Nanchen D, Gussekloo J, Cornuz J \& Rodondi N. Meta-analysis: subclinical thyroid dysfunction and the risk for coronary heart disease and mortality. Annals of Internal Medicine 2008 148 832-845. (doi:10.7326/0003-4819-148-11200806030-00225)

5 Rodondi N, den Elzen WP, Bauer DC, Cappola AR, Razvi S, Walsh JP, Asvold BO, Iervasi G, Imaizumi M, Collet TH et al. Subclinical hypothyroidism and the risk of coronary heart disease and mortality. Journal of the American Medical Association 2010 304 1365-1374. (doi:10.1001/jama.2010.1361)

6 Gencer B, Collet T-H, Virgini V, Bauer DC, Gussekloo J, Cappola AR, Nanchen D, den Elzen WPJ, Balmer P, Luben RN et al. Subclinical thyroid dysfunction and the risk of heart failure events: an individual participant data analysis from six prospective cohorts. Circulation $2012 \mathbf{1 2 6}$ 1040-1049. (doi:10.1161/CIRCULATIONAHA.112.096024)

7 Cooper DS \& Biondi B. Subclinical thyroid disease. Lancet 2012 379 1142-1154. (doi:10.1016/S0140-6736(11)60276-6)

8 Somwaru LL, Rariy CM, Arnold AM \& Cappola AR. The natural history of subclinical hypothyroidism in the elderly: the cardiovascular health study. Journal of Clinical Endocrinology and Metabolism 201297 1962-1969. (doi:10.1210/jc.2011-3047)

9 Surks MI \& Boucai L. Age- and race-based serum thyrotrophin reference limits. Journal of Clinical Endocrinology and Metabolism 201095 496-502. (doi:10.1210/jc.2009-1845)

10 Bremner AP, Feddema P, Leedman PJ, Brown SJ, Beilby JP, Lim EM, Wilson SG, O'Leary PC \& Walsh JP. Age-related changes in thyroid function: a longitudinal study of a community-based cohort. Journal of Clinical Endocrinology and Metabolism 201297 1554-1562. (doi:10.1210/jc.2011-3020)

11 Waring AC, Arnold AM, Newman AB, Buzkova P, Hirsch C \& Cappola AR. Longitudinal changes in thyroid function in the 
oldest old and survival: the Cardiovascular Health Study All-Stars Study. Journal of Clinical Endocrinology and Metabolism 201297 3944-3950. (doi:10.1210/jc.2012-2481)

12 Gammage MD, Parle JV, Holder RL, Roberts LM, Hobbs FD, Wilson S, Sheppard MC \& Franklyn JA. Association between serum free thyroxine concentration and atrial fibrillation. Archives of Internal Medicine $2007 \mathbf{1 6 7}$ 928-934. (doi:10.1001/archinte. 167.9.928)

13 Murphy E, Gluer CC, Reid DM, Felsenberg D, Roux C, Eastell R \& Williams GR. Thyroid function within the upper normal range is associated with reduced bone mineral density and an increased risk of nonvertebral fractures in healthy euthyroid postmenopausal women. Journal of Clinical Endocrinology and Metabolism 2011 95 3173-3181. (doi:10.1210/jc.2009-2630)

14 Yeap BB, Alfonso H, Chubb SAP, Puri G, Hankey GJ, Flicker L \& Almeida OP. Higher free thyroxine levels predict increased incidence of dementia in older men. The Health In Men Study. Journal of Clinical Endocrinology and Metabolism $2012 \mathbf{9 7}$ E2230-E2237. (doi:10.1210/jc.2012-2108)

15 Gussekloo J, van Exel E, de Craen AJ, Meinders AE, Frolich M \& Westendorp RG. Thyroid status, disability and cognitive function, and survival in old age. Journal of the American Medical Association 2004292 2591-2599. (doi:10.1001/jama.292.21.2591)

16 van den Beld AW, Visser TJ, Feelders RA, Grobbee DE \& Lamberts SWJ. Thyroid hormone concentrations, disease, physical function, and mortality in elderly men. Journal of Clinical Endocrinology and Metabolism 200590 6403-6409. (doi:10.1210/ jc.2005-0872)

17 Waring AC, Harrison S, Samuels MH, Ensrud KE, LeBlanc ES, Hoffman AR, Orwoll E, Fink HA, Barrett-Connor E \& Bauer DC. Thyroid function and mortality in older men: a prospective study. Journal of Clinical Endocrinology and Metabolism 201297 862-870. (doi:10.1210/jc.2011-2684)

18 Norman PE, Flicker L, Almeida OP, Hankey GJ, Hyde Z \& Jamrozik K. Cohort profile: the Health In Men Study (HIMS). International Journal of Epidemiology 200938 48-52. (doi:10.1093/ije/dyn041)

19 Charlson ME, Pompei P, Ales KL \& MacKenzie CR. A new method of classifying prognostic comorbidity in longitudinal studies: development and validation. Journal of Chronic Diseases 198740 373-383. (doi:10.1016/0021-9681(87)90171-8)

20 Holman CD, Bass AJ, Rosman DL, Smith MB, Semmens JB, Glasson EJ, Brook EL, Trutwein B, Rouse IL, Watson CR et al. A decade of data linkage in Western Australia: strategic design, applications and benefits of the WA data linkage system. Australian Health Review 200832 766-777. (doi:10.1071/AH080766)

21 Yeap BB, Alfonso H, Chubb SA, Walsh JP, Hankey GJ, Almeida OP \& Flicker L. Higher free thyroxine levels are associated with frailty in older men. The Health In Men Study. Clinical Endocrinology 201276 741-748. (doi:10.1111/j.1365-2265.2011.04290.x)

22 Li M, Eastman CJ, Waite KV, Ma G, Zacharin MR, Topliss DJ, Harding PE, Walsh JP, Ward LC, Mortimer RH et al. Are Australian children iodine deficient? Results of the Australian National Iodine Nutrition Study Medical Journal of Australia 2006184 165-169.

23 Asvold BO, Bjoro T, Nilson TI, Gunnell D \& Vatten LJ. Thyrotrophin levels and risk of fatal coronary heart disease. Archives of Internal Medicine 2008168 855-860. (doi:10.1001/archinte.168.8.855)

24 Parle JV, Maisonneuve P, Sheppard MC, Boyle P \& Franklyn JA. Prediction of all-cause and cardiovascular mortality in elderly people from one low serum thyrotrophin result: a 10-year cohort study. Lancet 2001358 861-865. (doi:10.1016/S0140-6736 (01)06067-6)

25 Cappola AR, Fried LP, Arnold AM, Danese MD, Kuller LH, Burke GL, Tracy RP \& Ladenson PW. Thyroid status, cardiovascular risk, and mortality in older adults. Journal of the American Medical Association 2006295 1033-1041. (doi:10.1001/jama. 295.9.1033)

26 Rodondi N, Newman AB, Vittinghoff E, de Rekeneire N, Satterfield S, Harris TB \& Bauer DC. Subclinical hypothyroidism and risk of heart failure, other cardiovascular events, and death. Archives of Internal Medicine $2005 \mathbf{1 6 5}$ 2460-2466. (doi:10.1001/archinte.165.21.2460)
27 Walsh JP, Bremner AP, Bulsara MK, O'Leary P, Leedman PJ, Feddema P \& Michelangeli V. Subclinical thyroid dysfunction as a risk factor for cardiovascular disease. Archives of Internal Medicine 2005165 2467-2472. (doi:10.1001/archinte.165.21.2467)

28 Iervasi G, Molinaro S, Landi P, Taddei MC, Galli E, Mariani F, L'Abbate A \& Pingitore A. Association between increased mortality and mild thyroid dysfunction in cardiac patients. Archives of Internal Medicine 2007167 1526-1532. (doi:10.1001/archinte.167.14. 1526)

29 Boekholdt SM, Titan SM, Wiersinga W, Chatterjee K, Basart DC, Luben R, Wareham NJ \& Khaw K-T. Initial thyroid status and cardiovascular risk factors: the EPIC-Norfolk prospective population study. Clinical Endocrinology 201072 404-410. (doi:10.1111/j.1365-2265.2009.03640.x)

30 Ittermann T, Haring R, Sauer S, Wallaschofski H, Dorr M, Nauck M \& Volzke H. Decreased serum TSH levels are not associated with mortality in the adult northeast German population. European Journal of Endocrinology 2010162 579-585. (doi:10.1530/EJE-090566)

31 Sgarbi JA, Matsumura LK, Kasamatsu TS, Ferreira SR \& Maciel RM. Subclinical thyroid dysfunctions are independent risk factors for mortality in a 7.5 year follow-up: the JapaneseBrazilian thyroid study. European Journal of Endocrinology 2010 162 569-577. (doi:10.1530/EJE-09-0845)

32 De Jongh RT, Lips P, van Schoor NM, Rijs KJ, Deeg DJ, Comijs HC, Kramer MH, Vandenbroucke JP \& Dekkers OM. Endogenous subclinical thyroid disorders, physical and cognitive function, depression and mortality in older individuals. European Journal of Endocrinology 2011165 545-554. (doi:10.1530/EJE-11-0430)

33 Hyland KA, Arnold AM, Lee JS \& Cappola AR. Persistent subclinical hypothyroidism and cardiovascular risk in the elderly: the cardiovascular health study. Journal of Clinical Endocrinology and Metabolism 201398 533-540. (doi:10.1210/ jc.2012-2180)

34 Razvi S, Shakoor A, Vanderpump M, Weaver JU \& Pearce SH. The influence of age on the relationship between subclinical hypothyroidism and ischemic heart disease: a metaanalysis. Journal of Clinical Endocrinology and Metabolism 200893 2998-3007. (doi:10.1210/jc.2008-0167)

35 Barr EL, Tonkin AM, Welborn TA \& Shaw JE. Validity of selfreported cardiovascular disease events in comparison to medical record adjudication and a statewide hospital morbidity database: the AusDiab Study. Internal Medicine Journal 200939 49-53. (doi:10.1111/j.1445-5994.2008.01864.x)

36 Hawkins RC. Furosemide interference in newer free thyroxine assays. Clinical Chemistry $1998 \mathbf{4 4} 2550-2551$.

37 Roos A, Bakker SJ, Links TP, Gans RO \& Wolffenbuttel BH. Thyroid function is associated with components of the metabolic function in euthyroid subjects. Journal of Clinical Endocrinology and Metabolism 200792 491-496. (doi:10.1210/jc.2006-1718)

38 Garduno-Garcia Jde J, Alvirde-Garcia U, Lopez-Carrasco G, Mendoza MEP, Mehta R, Arellano-Campos O, Choza R, Sauque L, Garay-Sevilla ME et al. TSH and free thyroxine concentrations are associated with differing metabolic markers in euthyroid subjects. European Journal of Endocrinology 2010163 273-278. (doi:10.1530/EJE-10-0312)

39 Klein I \& Danzi S. Thyroid disease and the heart. Circulation 2007 116 1725-1735. (doi:10.1161/CIRCULATIONAHA.106.678326) 40 Cooper C, Dere W, Evans W, Kanis JA, Rizzoli R, Sayer AA, Sieber CC, Kaufman J-M, Van Kan GA, Boonen S et al. Frailty and sarcopenia: definitions and outcome parameters. Osteoporosis International 201223 1839-1848. (doi:10.1007/s00198-0121913-1)

Received 11 April 2013

Revised version received 21 June 2013

Accepted 12 July 2013 